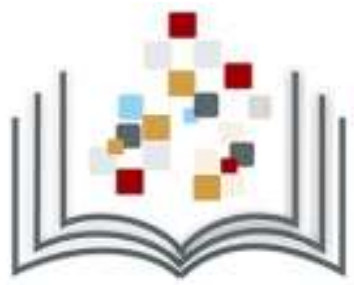

\title{
1936 - 2016: 80 ANOS DA REVISTA DAE - O PERIÓDICO DE ENGENHARIA DA SABESP
}

lara Regina Soares Chao ${ }^{*}$

1SABESP- Departamento de Prospecção Tecnológica e Propriedade Intelectual - São Paulo (SP) - Brasil

*Autor correspondente: ichao@sabesp.com.br

\section{Como citar:}

CHAO, lara Regina Soares. 1936 - 2016: 80 anos da revista dae - o periódico de engenharia da sabesp. In: WORKSHOP DE EDITORAÇÃO CIENTÍFICA, 9., 2016, São Paulo. Anais... São Paulo: Associação Brasileira de Editores Científicos, 2016. p. 1-6 DOI: http://dx.doi.org/10.21452/wec.IXwec.2016.0001

\section{RESUMO}

A experiência de produzir uma revista de excelência passa por inúmeras etapas e desafios para garantir a qualidade do conteúdo. A busca pela melhoria contínua e constante aperfeiçoamento constitui-se em uma tarefa diária para os editores científicos. O texto mostra os desafios de produzir e conduzir uma revista técnico-científica de qualidade e como estes se alteram e se sofisticam ao longo do tempo. Discute a qualidade do conteúdo e a importância de atualizar-se a estrutura organizacional. Aborda também, o sistema de submissão de artigos, o desafio da indexação e as dificuldades do editor para manter a atratividade do público operacional por uma revista técnico-científica.

\section{INTRODUÇÃO}

A Revista DAE, o periódico de engenharia da Companhia de Saneamento Básico do Estado de São Paulo (Sabesp), completa 80 anos de existência em 2016 e comemora a conquista de ser a mais antiga revista de engenharia sanitária do Brasil. Os desafios para a manutenção de um periódico de tão longo alcance foram mudandos ao longo dos anos, resultado das diversas adequações necessárias para busca da qualidade exigida para uma revista técnico-científica.

Se em 1936, quando a revista foi criada, o desafio era a obtenção de um veículo para disseminação de ideias e propostas capazes de escoar a produção científica de uma determinada área de desenvolvimento operacional, hoje essa concepção mudou, e muito. Atualmente, as revistas precisam de uma qualidade mínima para serem atrativas para os publicadores, de forma que mais autores queiram publicar seus artigos na revista e, assim, ser reconhecidos por essa publicação. Para valorizar a qualidade de conteúdo dos periódicos, a Coordenação de Aperfeiçoamento de Pessoal de Nível Superior (CAPES) estabeleceu critérios de qualidade para a classificação de revistas, trazendo uma pontuação diferenciada para atrair os pesquisadores para os periódicos mais bem classificados na escala proposta.

Dentro desse contexto, foi necessário reavaliar e adequar aos novos tempos aspectos como: a forma de encaminhar e avaliar os artigos; a busca por indexação dos periódicos a uma base de dados reconhecida; a criatividade da editoria para que a 
revista não fique restrita ao ambiente exclusivamente acadêmico, uma vez que o público-alvo desse tipo de periódico é misto, constituído por pesquisadores da área acadêmica, mas também e, preponderantemente, por técnicos de nível superior, responsáveis pela operação das instalações das companhias de saneamento.

\section{HISTÓRICO DA REVISTA DAE}

O lançamento da Revista DAE em 1936, então intitulada Boletim da RAE, constituiu um acontecimento pioneiro característico de uma época muito significativa do desenvolvimento da engenharia sanitária no Brasil. Nesse período, a Repartição de Águas e Esgotos de São Paulo assumiu o papel de uma verdadeira escola, de onde saíram grandes autoridades em sistemas de abastecimento e tratamento de águas e resíduos líquidos. Infelizmente, em fevereiro de 1994, a revista parou de circular e deixou uma lacuna nesse segmento editorial. Portanto, após ficar quase 14 anos desativada, a revista voltou a ser apresentada à comunidade técnica em agosto de 2007, para continuar registrando a história do setor, tendo como objetivo desafiador tornar-se uma das leituras mais importantes do núcleo de saneamento. Para alcançar essa meta, o primeiro passo dado foi compor um núcleo de excelência para a análise dos artigos, formado não só por representantes de São Paulo, mas também por professores de outros estados. Outros passos importantes foram a criação da revista em meio digital, disponibilizada no site da Revista DAE, pelo endereço www.revistadae.com.br, e a digitalização de todo o acervo desde 1936, o qual pode ser acessado e baixado gratuitamente.

\section{IMPORTÂNCIA DA QUALIDADE DO CONTEÚDO E ESTRUTURA ORGANIZACIONAL ADAPTADA AO PÚBLICO-ALVO}

Em uma primeira avaliação, podemos aferir que a Revista DAE cresceu nesses anos em tiragem de exemplares por edição e, também, no atendimento às normas de estruturação das revistas e apresentação dos artigos. Nesse contexto, foi necessário adaptar às exigências estabelecidas pelas diretrizes da CAPES para periódicos científicos. Outras necessidades de modernização para atendimento do público atual foram constatadas e implementadas. Para disponibilizar os artigos antigos para download, por exemplo, foi preciso revisar vários itens para sua adequação. Foram inseridos, no mínimo, resumos e palavras-chave, de forma a conseguir enquadrá-los em um sistema de busca on-line. Aliada a essa diretriz, houve a necessária adaptação ao público-alvo, constituído por dois ramos distintos: pesquisadores da área acadêmica e profissionais da área operacional das companhias de saneamento. Para atrair leitores com enfoques distintos, mas necessariamente complementares, para um periódico dessa natureza, foi necessário oferecer uma diversidade de seções. Além disso, considerou-se a necessidade de textos com linguagem mais coloquial, entrevistas, ensaios, além de divulgação de eventos e publicações para atrair os leitores da área operacional e incentivá-los a produzir textos de excelência, porém, sem o rigor da estrutura acadêmica. Assim, atualmente, a revista conta com as seguintes seções:

edição;

Editorial: breve apresentação dos artigos técnicos e jornalísticos presentes na

- Ponto de vista ou matéria de capa: artigo autoral escrito por um especialista de notório saber sobre o assunto em pauta na área de saneamento ambiental;

- Notícias: breves considerações a respeito de um tema, com o único intuito de informar a respeito de um fato ou dado curioso. Este espaço é composto por notícias do setor que tendem para o inusitado. Não é um fórum de discussão técnica e, sim, uma coluna de entretenimento, mas com notícias interessantes e verídicas;

- $\quad$ Calendário de eventos: calendário de fóruns, seminários, palestras, etc, que irão acontecer tanto no Brasil quanto em outros países; 
- Resenhas de publicações: resenhas de livros lançados recentemente, contendo a referência bibliográfica do autor e um resumo conclusivo da obra. A coluna não faz análise crítica do livro, mas sim divulga o que há de novo no mercado;

- Ensaio: apresentação de textos opinativos sobre temas relevantes para a engenharia sanitária e ambiental. Os textos são escolhidos pelo Conselho Editorial e abordados por, no mínimo, dois autores;

- Artigo técnico: exposição completa e original, totalmente documentada e interpretada, de um trabalho de relevância;

- Nota técnica: trabalho sumário que pode corresponder a artigo com resultados ainda parciais, considerações sobre aspectos pouco abrangentes da área, desenvolvimento de considerações técnicas relativas a algum aspecto da engenharia sanitária e ambiental ou outra abordagem sumária pertinente, a juízo dos editores;

- Revisão da literatura: artigo no qual é levantado o estado da arte de algum tema relevante e inovador na área de engenharia sanitária e ambiental, cuja abordagem deve ser suficientemente crítica e capaz de identificar avanços, lacunas e desafios científicos no tema, à luz da literatura nacional e internacional. Trabalhos de revisão sistemática e metanálise podem ser incluídos nesta categoria de artigo;

- Discussão: avaliação crítica ou ampliação do conteúdo de uma nota técnica, artigo técnico ou revisão da literatura publicada na revista. As discussões são publicadas, sempre que possível, com a resposta dos autores. Não são aceitos relatórios, traduções nem artigos já publicados ou submetidos à publicação em outros veículos, ou que impliquem promoção comercial de determinada marca, produto ou empresa;

- Práticas operacionais e de empreendimentos: objetiva publicar trabalhos teóricos e aplicados, produzidos pelos técnicos da área operacional das companhias de saneamento básico, com o intuito de promover a disseminação do conhecimento gerado nelas. Nesta seção, são aceitos trabalhos sem o rigor da estrutura acadêmica. Os trabalhos submetidos devem ser originais e não devem ter sido aceitos para publicação (ou publicados) por outras revistas, nem devem estar em processo de avaliação para publicação em outro meio. Além da originalidade e relevância, são levadas em conta a qualidade da apresentação (clareza, estilo e organização do texto) e a adequação do texto aos interesses do público leitor do periódico.

\section{PÚBLICO-ALVO}

Temos como público-alvo; profissionais das empresas de saneamento básico, docentes e alunos de pós-graduação, pesquisadores e gestores de instituições de ensino superior e de pesquisa, gestores de associações científicas e profissionais, dirigentes e técnicos de órgãos do Ministério das Cidades (MCid), do Meio Ambiente (MMA) e do Ministério de Ciência, Tecnologia e Inovação (MCTI), bem como da Agência Nacional de Águas (ANA) e demais órgãos envolvidos na formação de pessoal e produção científica.

A Revista DAE também é divulgada para organizações não governamentais que atuam na área de meio ambiente, para as empresas de saneamento públicas e privadas, para as universidades e bibliotecas que mantêm faculdades de engenharia, biologia e meio ambiente, para comitês de bacias, fornecedores de insumos voltados ao setor, representantes de classe, secretarias municipais e estaduais de saneamento e meio ambiente, sindicatos, representantes da vigilância sanitária, entre outros.

\section{SISTEMA DE SUBMISSÃO DE ARTIGOS - APROVAÇÃO E REPROVAÇÃO}

Para que um artigo técnico seja passível de publicação, este é submetido à avaliação de um núcleo de pareceristas, que tem como referência os seguintes critérios gerais: o artigo deve abordar temas de relevante interesse à área de engenharia sanitária e ambiental; se encontrar em estágio de desenvolvimento tecnológico que permita sua utilização em escala real (a revista não é um veículo de divulgação de estudos que ainda estejam na fase de pesquisa básica); ser inédito. 
Para submissão de artigos à revista, os autores devem enviar seus trabalhos e acompanhar cada passo da avaliação no endereço www.revistadae.com.br (e tão somente por ele). O texto recebido é então encaminhado para dois pareceristas que atuam na área e, no caso de divergência de parecer, o artigo é encaminhado para um terceiro avaliador. Existe também a possibilidade de os pareceristas solicitarem alterações ou informações complementares, visando a melhoria do artigo, com vista à sua aprovação. O processo de avaliação é duplo-cego, mantendo-se, assim, a confidencialidade das informações. Os artigos aprovados entram em uma lista cronológica e automática de publicação. Essa lista é pública e fica disponível no site oficial da Revista DAE

\section{GRANDES DESAFIOS: O ÁRDUO CAMINHO DA REVISTA DAE PARA SE QUALIFICAR E SER INDEXADA A BASES DE DADOS NACIONAIS E INTERNACIONAIS}

O crescimento da produção científica tem exigido a indexação dos periódicos em diretórios e portais para que a informação se torne visível à comunidade científica de forma rápida e sistemática. Um sistema de indexação tem por objetivo principal assegurar a recuperação de qualquer documento ou informação no momento em que um usuário busque um assunto em sistema de informação (TRZESNIAK, PLATACAVIEDES, \& CORDOBA-SALGADO, 2012).

A importância da indexação a bancos de dados nacionais e internacionais propicia um atrativo aos autores, pois seus artigos passam a ter fator de impacto significativo. Segundo Braile (2007, p. 341), a indexação de uma revista às bases de dados significa "[...] reconhecimento de mérito, aval à qualidade de seus artigos e consequentemente para seus autores, que normalmente estão submetidos a processos de mensuração de desempenhos de atividades, tanto acadêmicos como de serviços".

A Revista DAE está indexada a dois diretórios: Latindex e Diadorim. A falta de indexação em um amplo leque de banco de dados gera um entrave para o recebimento de publicações. É muito comum ouvirmos a alegação de pesquisadores da área acadêmica de que não publicam a quantidade de artigos que gostariam na Revista DAE em razão de a revista ainda não ser indexada a bases, como SciELO, Scopus, Google Scholar ou o Journal Citation Reports (JCR). Isso gera um círculo vicioso que pode comprometer a almejada posição desejável, pois os pesquisadores precisam encaminhar suas pesquisas para revistas que tenham a qualificação para receberem pontuação; por outro lado, a revista só conseguirá a qualificação se divulgar artigos de relevância.

É amplamente reconhecido que o sistema Qualis implantado pela CAPES tem desempenhado papel fundamental no aprimoramento do sistema de qualificação dos periódicos no país. Por esse motivo, a obtenção da certificação Qualis e a indexação bibliográfica às principais bases de periódicos passaram a ser grandes metas a serem alcançadas pela editoria da revista como prioridade, em sua busca por excelência e cumprimento de sua missão. A Revista DAE está qualificada pela CAPES como periódico B3 (relevância média). Hoje a Revista DAE conta com um software de acesso livre, (Open Resource) que atende boa parte dos requisitos das principais bases de indexação, porém não está padronizado com uma interface amigável com os principais buscadores da web como, Bing, Google Scholar, etc. Esse é um dos grandes desafios para a editoria da Revista DAE; inseri-la no Sistema Open Journal System (OJS), para facilitar sua captura com os principais buscadores da web e consequentemente aumentar sua visibilidade. 


\section{OUTROS DESAFIOS: DIFICULDADES DO EDITOR PARA MANTER A ATRATIVIDADE DE UMA REVISTA TÉCNICO-CIENTÍFICA NO MEIO OPERACIONAL}

O grande desafio aqui é: como conquistar artigos da área operacional? Como atrair o pessoal de "campo" a colocar suas ideias e feitos em papel? Quais são os entraves? Quais são as dificuldades do editor para manter a atratividade de uma revista técnico-científica no meio operacional?

As visões acadêmicas e profissionais nesse segmento são muito diferentes. Enquanto na área acadêmica publicar em periódicos significa aumento de pontuação, com reflexos diretos na carreira, na área profissional, no dia a dia de profissionais de concessionárias de serviços de saneamento, por exemplo, encaminhar o artigo para um congresso traz muito mais retorno e possibilidades de networking do que publicar em um periódico. Como reverter isso? O que pode ser oferecido? Quais são as vantagens?

Uma tentativa para solucionar essa importante dificuldade foi a criação de uma seção intitulada "Práticas operacionais e de Empreendimentos. Neste espaço podem ser encaminhados artigos que descrevam experiências práticas operacionais e práticas construtivas empregadas na engenharia sanitária, como por exemplo, novos métodos construtivos utilizados em empreendimentos de saneamento e estudos de casos operacionais. Este tipo de texto possui uma estrutura que não mantém total similaridade com os artigos técnicos de cunho acadêmico, principalmente em relação aos itens de metodologia e conclusão. Mas, apesar de tais estudos não seguirem o rigor dos artigos técnicos convencionais, se reportam a experiências que são de grande interesse para o setor. Esta seção visa, preponderantemente, ampliar o nosso acervo de experiências em saneamento, no sentido de demonstrar e informar sobre as inúmeras dificuldades de ordem cultural, econômica, operacional e construtiva que ocorreram e que ainda ocorrem em diversas áreas de interesse. A mudança foi feita com a prévia autorização do Conselho Editorial da revista, e vale ressaltar que os artigos que se enquadram nesta nova seção também são submetidos à aprovação de pareceristas e seguem os trâmites de avaliação adotados desde o relançamento da Revista DAE.

Vale ressaltar que a Sabesp, ao reeditar a Revista DAE, se propôs a ser uma das porta-vozes da evolução do saneamento, com suas novas tecnologias aplicadas, avanços nos sistemas de tratamento de águas e de esgotos, processos de qualidade, programas e projetos em pleno desenvolvimento, etc. Mas, acima de tudo, a partir da circulação desta publicação entre companhias de saneamento, universidades, institutos de pesquisa, organizações não governamentais e públicos de interesse, a Companhia tem a intenção de assegurar que todos esses avanços auxiliem na construção de um saneamento universalizado, gerador de soluções socioambientais para 0 aprimoramento da qualidade de vida de toda sociedade. Nesse sentido, a participação do público é de fundamental importância para que possamos desenvolver um conteúdo dinâmico e referencial para a classe.

\section{CONCLUSÕES}

Este artigo procurou mostrar o quanto é complexo manter um periódico de qualidade e o quanto é importante a busca contínua de melhorias que atendam às expectativas da comunidade técnico-científica. Muitas são as opções para elevar o padrão do periódico e aumentar o interesse dos autores, mas sem dúvida a indexação a bases de dados reconhecidas nacional e internacionalmente, a atribuição de registro DOI, a periodicidade, credibilidade, disponibilidade on line e o primor na qualidade, em todas as etapas de produção, são formas eficientes de promover um periódico para ser reconhecido pela comunidade técnico-científica. 


\section{REFERÊNCIAS}

BRAILE, Domingo M.; BRANDAU, Ricardo; MONTEIRO, Rosangela. A importância da indexação para as revistas científicas. Rev. Bras. Cardiol. Invasiva, [s.I.], v. 15, n. 4, p.341-342, 2007. Elsevier BV. http://dx.doi.org/10.1590/s2179-83972007000400006

TRZESNIAK, Piotr. A concepção e a construção da revista científica, in: II Encontro de editoração Cientifica e Cultural/IV Feira Pan - Amazônica do livro. 2000. Belém/PA: MPEG - Museu Paranaense Emilio Goeldi/ABEC - Associação Brasileira de Editores Científicos. (Anais) p 21-34. Disponível em:

<https://www.academia.edu/872626/A concep\%C3\%A7\%C3\%A30 e a constru\%C3 \%A7\%C3\%A3o da revista cient\%C3\%ADfica>. Acesso em:26 out 2015.

TRZESNIAK, Piotr; PLATA-CAVIEDES, Tatiana; CÓRDOBA-SALGADO, Oscar Alejandro. Qualidade de Conteúdo, o Grande Desafio para os Editores Científicos.

Revista Colombiana de Psicología, Colombia, v. 21, p.57-78, 2012. Disponível em: $<$ http://www.revistas.unal.edu.co/index.php/psicologia/article/view/31032/34502>. Acesso em: 26 out. 2015

ROSA, Antonio Marques da; CHACHAMOVICH, Júlio. O que faz a excelência de uma revista científica. Rev. Psiquiatr. Rio Gd. Sul, [s.I.], v. 25, n. 2, p.253-256, ago. 2003. FapUNIFESP (SciELO). http://dx.doi.org/10.1590/s0101-81082003000200002

PALAVRAS-CHAVE: Revistas científicas. Avaliação de trabalhos científicos. Revista DAE. 